\title{
Chemistry of Nanomaterial in Supramolecular System
}

\author{
Keyur D Bhatt* \\ Department of Chemistry, India \\ *Corresponding author: Keyur D Bhatt, Department of Chemistry, Gujarat, India
}

Submission: 梅 March 26, 2018; Published: 㘹 May 23, 2018

\begin{abstract}
Design, synthesis and manipulation of nano- materials derived from supramolecular system have found remarkable interest in recent times because of its wide applications in Pharmaceuticals sciences, sensor and biology. The advanced size and shape-dependent properties of nano-materials have significantly impacted all spheres of human life and environment making nanotechnology a promising field for biomedical and chemical applications.

Keywords: Supramolecular chemistry; Nanomaterial; Calix system; Applications
\end{abstract}

\section{Introduction}

Supramolecular chemistry is a comparatively advanced field of nanoscience which focuses moderately literally ongoing "chemistry beyond molecule". It can be described as the study of systems which contain more than two molecules, and it purposes to understand the structure, modification, function, and properties of this system. Supramolecular chemistry arose when nanoscience had become a relatively mature subject and the synthesis and properties of supramolecular compounds had become well understood [1]. Now a day, the synthesis of nanomaterial have attracted increasing interest because of their unique properties and promising applications [2,3]. The synthetic technique for fabricating nanoparticles and nanomaterial involved the reduction of highly positive charged metal salts in presence of stabilizing or capping agent, which prevents them from combination and allows isolation of nanoparticles [4,5]. Among all, organic molecules have gained much attention because of their prospective and advanced application in both stabilizing as well as capping agent [6-9]. Surfactants [10] were highly effective at stabilizing metal nanoparticles of different sizes, creating opportunities to fabricate well-defined nanostructures with size-tunable materials properties [11-13]. The study of the dispersion and stability of heteroatoms containing encapsulated gold, silver and palladium nanoparticles through extracting metal particles from hydrosol into toluene or chloroform using organic derivative surfactant as an extracting have also been done and it was revealed that the many systems (calix, hetero ring, polymers etc.) surfactants [14] with sulphur functionalized head groups could make the mid nanometer sized gold particles dispersed in organic solvents (Figure 1).

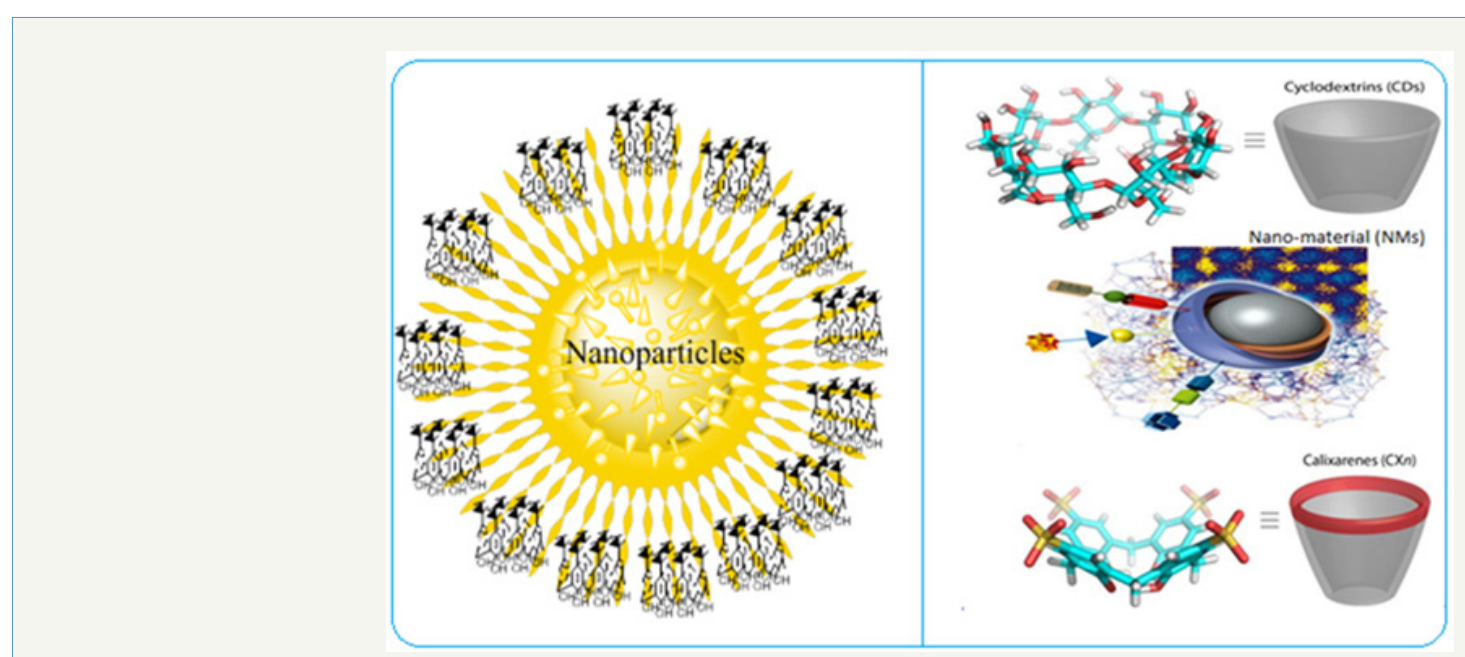

Figure 1 
Supramolecules have received much attention in the recent past for their use as reducing as well as stabilising agent for the preparation of metal nanoparticles [7,15]. Metal nanoparticles are the most widely examined nano-materials due to their unique optical properties, which can be applied in various applications such as bio-sensing, detecting of elements and imaging techniques. Supramolecules reduced nanoparticles find application in the fields of catalysis [4], pharmaceutical science [16], environmental science [17], inorganic drug chemistry, Biomolecular chemistry, biomedicine and physical chemistry $[4,18]$ etc.

\section{Conclusion}

Here we showed various applications of nanomaterials of interest in supramolecular chemistry, mainly calix system, nanoparticles. Supramolecular chemistry deceptions behind any of these processes and it is essential to any successful approach leading to new and promising nanomaterials synthesized from supramolecules.

\section{References}

1. Wang X, Qu K, Xu B, Ren J, Qu X (2011) Multicolor luminescent carbon nanoparticles: synthesis, supramolecular assembly with porphyrin, intrinsic peroxidase-like catalytic activity and applications. Nano Research 4(9): 908-920.

2. Bhatt KD, Makwana BA, Vyas DJ, Mishra DR, Jain VK (2014) Selective recognition by novel calix system: ICT based chemosensor for metal ions. Journal of Luminescence 146: 450-457.

3. Bhatt KD, Vyas DJ, Makwana BA, Darjee SM, Jain VK (2014) Highly stable water dispersible calix [4] pyrrole octa-hydrazide protected gold nanoparticles as colorimetric and fluorometric chemosensors for selective signaling of Co (II) ions. Spectrochimica Acta Part A: Molecular and Biomolecular Spectroscopy 121: 94-100.

4. Daniel MC,Astruc D (2004) Gold nanoparticles: assembly, supramolecular chemistry, quantum-size-related properties, and applications toward biology, catalysis, and nanotechnology. Chemical Reviews 104(1): 293346.

5. Hu QD, Tang GP, Chu PK (2014) Cyclodextrin-based host-guest supramolecular nanoparticles for delivery: from design to applications. Accounts of Chemical Research 47(7): 2017-2025.

6. Bar H, Bhui DK, Sahoo GP, Sarkar P, De SP, et al. (2009) Green synthesis of silver nanoparticles using latex of Jatropha curcas. Colloids and surfaces A: Physicochemical and Engineering Aspects 339(1-3): 134-139.
7. Lowe AB, Sumerlin BS, Donovan MS, McCormick CL (2002) Facile preparation of transition metal nanoparticles stabilized by welldefined (co) polymers synthesized via aqueous reversible additionfragmentation chain transfer polymerization. Journal of the American Chemical Society 124(39): 11562-11563.

8. Raveendran P, Fu J, Wallen SL (2003) Completely "green" synthesis and stabilization of metal nanoparticles. Journal of the American Chemical Society 125(46): 13940-13941.

9. Wangoo N, Bhasin K, Mehta S, Suri CR (2008) Synthesis and capping of water-dispersed gold nanoparticles by an amino acid: bioconjugation and binding studies. Journal of Colloid and Interface Science 323(2): 247-254.

10. Maestro A, Guzmán E, Santini E (2012) Wettability of silica nanoparticlesurfactant nanocomposite interfacial layers. Soft Matter 8(3): 837-843.

11. Bhatt KD, Vyas DJ, Makwana BA, Darjee SM, Jain VK, et al. (2016) Turnon fluorescence probe for selective detection of $\mathrm{Hg}$ (II) by calixpyrrole hydrazide reduced silver nanoparticle: Application to real water sample. Chinese Chemical Letters 27(5): 731-737.

12. Makwana BA, Vyas DJ, Bhatt KD, Darji S, Jain VK (2016) Novel fluorescent silver nanoparticles: sensitive and selective turn off sensor for cadmium ions. Applied Nanoscience 6(4): 555-566.

13. Vyas DJ, Makwana BA, Gupte HS, Bhatt KD, Jain VK (2012) An efficient one pot synthesis of water-dispersible calix [4] arene polyhydrazide protected gold nanoparticles-A "turn off" fluorescent sensor for Hg [II] ions. Journal of Nanoscience and nanotechnology 12(5): 3781-3787.

14. Kawai T, Neivandt DJ, Davies PB (2000) Sum frequency generation on surfactant-coated gold nanoparticles. Journal of the American Chemical Society 122(48): 12031-12032.

15. Lévy R, Thanh NT, Doty RC, Hussain I, Nichols RJ, etal. (2004) Rational and combinatorial design of peptide capping ligands for gold nanoparticles. Journal of the American Chemical Society 126(32): 10076-10084.

16. Ostroverkhova $O$ (2013) Handbook of organic materials for optical and (opto) electronic devices: properties and applications. Elsevier, USA.

17. Moore M (2006) Do nanoparticles present ecotoxicological risks for the health of the aquatic environment? Environment International 32(8): 967-976.

18. Descalzo AB, Máñez RM, Sancenon F, Hoffmann K, Rurack K (2006) The supramolecular chemistry of organic-inorganic hybrid materials. Angew Chem Int Ed Engl 45(36): 5924-5948.
Creative Commons Attribution 4.0 International License

For possible submissions Click Here

\section{Submit Article}

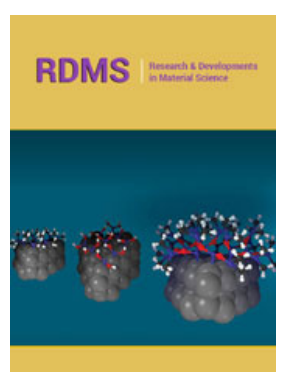

\section{Research \& Development in Material Science}

\section{Benefits of Publishing with us}

- High-level peer review and editorial services

- Freely accessible online immediately upon publication

- Authors retain the copyright to their work

- Licensing it under a Creative Commons license

- Visibility through different online platforms 